\title{
Fast, sensitive and selective liquid chromatographic-tandem mass spectrometric determination of tumor-promoting diterpene esters ${ }^{1}$
}

\author{
G. VOGG, S. ACHATZ, A. KETTRUP, and H. SANDERMANN JR. ${ }^{2}$ \\ Vogg and Sandermann, Institute of Biochemical Plant Pathology, GSF-National Research Center for Environment and \\ Health, D-85764 Oberschleissheim, Germany. Achatz and Kettrup, Institute of Ecological Chemistry, GSF-National \\ Research Center for Environment and Health, D-85764 Oberschleissheim, Germany.
}

\begin{abstract}
:
A liquid chromatography-tandem mass spectrometry (LC-MS-MS) method was developed to detect tumor-promoting diterpene esters of the tigliane and ingenane types within plant extracts. Fractionation on a $\mathrm{C}_{18}$ high-performance liquid chromatography (HPLC) column was followed by MS-MS-multiple reaction monitoring (MRM) using the precursor $\rightarrow$ product ion pairs of $m / z 311 \rightarrow 293$ and $293 \rightarrow 265$ for phorbol esters. The ion pairs $m / z \quad 313 \rightarrow 295$ and $295 \rightarrow 267$ were used for ingenol and deoxyphorbol esters. In a second run, the characteristic ions at $m / z 311$ and 313 were followed in precursor ion scan mode. These quasi-molecular ions were utilized to obtain full scan spectra of the compounds in product ion scan mode. Due to its selectivity, the present on-line method can be applied for plant cultivar selection and plant product control without timeconsuming extraction procedures and complex bioassays.
\end{abstract}

\section{Keywords:}

Euphorbia leuconeura; Croton oil; Oils; Plant materials; Diterpenes; Terpenes; Phorbol; Ingenol.

\footnotetext{
${ }^{1}$ Received 15 March 1999; received in revised form 10 June 1999; accepted 10 June 1999.

${ }^{2}$ Corresponding author. Tel.: +49-89-3187-2285; fax: +49-893187-3383.

E-mail address: sandermann@gsfde (H. Sandermarm Jr.)
}

Page 1 of 12 